\title{
The Effect of Hot Deformation Parameters on Microstructure Evolution of the $\alpha$-Phase in Ti-6Al-4V
}

\begin{abstract}
BAMA PERUMAL, MARTIN A. RIST, SALIH GUNGOR, JEFFERY W. BROOKS, and MICHAEL E. FITZPATRICK

The effect of high-temperature deformation and the influence of hot working parameters on microstructure evolution during isothermal hot forging of Ti-6Al-4V in the alpha phase field were investigated. A series of hot isothermal axis-symmetric compression tests were carried out at temperatures both low and high in the alpha stability field $\left[\left(1153 \mathrm{~K}\right.\right.$ and $1223 \mathrm{~K}\left(880{ }^{\circ} \mathrm{C}\right.$ and $\left.950^{\circ} \mathrm{C}\right)$, respectively], using three strain rates $(0.01,0.1$ and $1.0 / \mathrm{s})$ relevant to industrial press forging. The microstructures and orientation of the alpha laths were determined using optical microscopy and electron backscatter diffraction techniques. The experimental results show that there is a change in lath morphology of the secondary $\alpha$ phase under the influence of the deformation parameters, and that $\alpha$ lath thickness appears to have little influence on flow behavior.
\end{abstract}

DOI: $10.1007 / \mathrm{s} 11661-016-3552-1$

(C) The Author(s) 2016. This article is published with open access at Springerlink.com

\section{INTRODUCTION}

TITANIUM alloys are widely used for many applications, especially in the aerospace industry owing to their combination of high strength, corrosion resistance, and low density. Among titanium alloys, the two-phase Ti-6Al-4V is the most popular, and an enormous amount of work has been done regarding the improvement of its mechanical properties through heat treatment, hot working, or a combination of these processes. The alloy can be tailored by altering microstructure and texture through thermo-mechanical processing (TMP) in order to control the mechanical properties during cooling from the beta phase field. The breakdown of the colony-alpha microstructure during $(\alpha+\beta)$ thermo-mechanical processing plays a pivotal role in obtaining a uniform, fine equiaxed alpha microstructure in forging bar and billet, plate, and other alpha/beta mill products. Most of the research in this area has focused on the workhorse alloy aerospace titanium alloy, Ti-6Al-4V. A number of investigators have examined the kinetics of the globularization

BAMA PERUMAL, Research Fellow, and JEFFERY W. BROOKS, Hanson Professor of Industrial Metallurgy, Director of the Partnership for Research in Simulation of Manufacturing and Materials (PRISM2), Director of the Centre for Advanced Simulation \& Modelling for Manufacturing CASiM2, are with the School of Metallurgy and Materials, University of Birmingham, Edgbaston, Birmingham B15 2TT, UK. Contact e-mails: b.perumal@bham.ac.uk, bamaperumal@gmail.com MARTIN A. RIST (late), and SALIH GUNGOR, Lecturers, are with Materials Engineering, The Open University, Walton Hall, Milton Keynes MK7 6AA, UK. MICHAEL E. FITZPATRICK, Executive Dean and Lloyd's Register Foundation Chair in Materials Fabrication and Engineering, is with the Faculty of Engineering and Computing, Coventry University, Priory Street, Coventry CV1 5FB, UK.

Manuscript submitted October 9, 2014.

Article published online May 13, 2016 of $(\alpha+\beta)$ titanium alloys during sub-transus hot working ${ }^{[1-3]}$ mainly using modes of loading such as uniaxial compression and tension during deformation. The possible mechanisms by which lamellar microstructures coarsen or transform to a globular morphology have been studied by various investigators. ${ }^{[4]}$

The present work was undertaken to quantify the effect of TMP parameters on the evolution of microstructure and orientation of alpha laths in two-phase $(\alpha+\beta)$ Ti-6Al-4V. The main objective of the work was to delineate the mechanism by which globularization occurs during TMP of two-phase $(\alpha+\beta)$ titanium alloy with a lamellar preform microstructure. Owing to its technical importance, the mechanism of the globularization process has been the subject of many studies over the years, but there have been a limited number of studies on deformation texture of Ti-6Al-4V during hot compression tests that simulate the forming process of components made from this alloy. The major contributions of this work are the identification of deformation and globularization mechanisms, and the understanding of the evolution of microstructure by studying the orientation distribution or rotation of the $\alpha$-phase during Ti-6Al-4V during deformation. Electron backscattered diffraction (EBSD) was used to study the alpha lath orientation of Ti-6Al-4V during hot working.

\section{MATERIAL AND EXPERIMENTAL PROCEDURE}

\section{A. Material}

The material used was $(\alpha+\beta)$ titanium alloy Ti-6Al-4V produced by TIMET UK Ltd and supplied by QinetiQ Ltd in the form of round bar with $40 \mathrm{~mm}$ 
diameter and length of about $90 \mathrm{~mm}$. The measured chemical compositions (wt pct) were $6.48 \mathrm{Al}, 3.99 \mathrm{~V}$, $0.22 \mathrm{Fe}, 0.16 \mathrm{O}, 0.002 \mathrm{~N}, 0.02 \mathrm{C}, 0.005 \mathrm{H}$, and balance titanium. The microstructure of the as-received Ti-6Al-4V alloy was composed of equiaxed $\alpha$ grains in a matrix of beta phases, as shown in Figure 1(a). The as-received material was heat treated to produce a lamellar structure by holding at a sub-transus temperature of $1223 \mathrm{~K}\left(950^{\circ} \mathrm{C}\right)$ for 10 minutes, then heating to a super-transus temperature of $1303 \mathrm{~K}\left(1030^{\circ} \mathrm{C}\right)$ for 2 minutes followed by water quenching. The heattreated specimens, characterized by an acicular microstructure, are shown in Figure 1(b).

\section{B. Hot Compression Tests}

In order to understand the initial globularization process, a series of hot compression 'upset' tests was carried out using a computer-controlled servo-hydraulic MTS $100 \mathrm{kN}$ machine coupled with an Instron Severn Furnaces Ltd Radiant Furnace model RHS1856A, at fixed nominal strain rates and temperatures relevant to industrial hydraulic press forging. For this purpose, cylindrical samples measuring $15.0 \mathrm{~mm}$ in height and
$10.0 \mathrm{~mm}$ diameter were manufactured using an electro-discharge machine (EDM), then heated to test temperature, soaked for 30 minutes, and upset under constant axial (true) strain- rate conditions. During hot compression testing, isothermal conditions were achieved using a Eurotherm 8-segment programmable controller (model 2408). The maximum rate for heating the test specimen to the test temperature was $1{ }^{\circ} \mathrm{C} / \mathrm{s}$.

Test temperatures both low and high in the $(\alpha+\beta)$ stability field, $1153 \mathrm{~K}$ and $1223 \mathrm{~K}\left(880^{\circ} \mathrm{C}\right.$ and $\left.950{ }^{\circ} \mathrm{C}\right)$, respectively, were chosen to investigate the effect of differing $\alpha / \beta$ phase proportions. Strain rates were 0.01 , 0.1 , and $1.0 \mathrm{~s}^{-1}$ and deformation was allowed to proceed to various strain levels $(0.1,0.2,0.4,0.7$, and 1.0) before being interrupted. After isothermal compression testing to the predetermined strain level, the cylindrical specimens were water quenched to room temperature. These specimens were axially sectioned parallel to the compression axis and prepared using standard metallographic techniques. For comparison, six additional samples were heated to deformation temperatures, given an identical soak, and water quenched to determine the undeformed microstructure. Following deformation, five selected specimens were
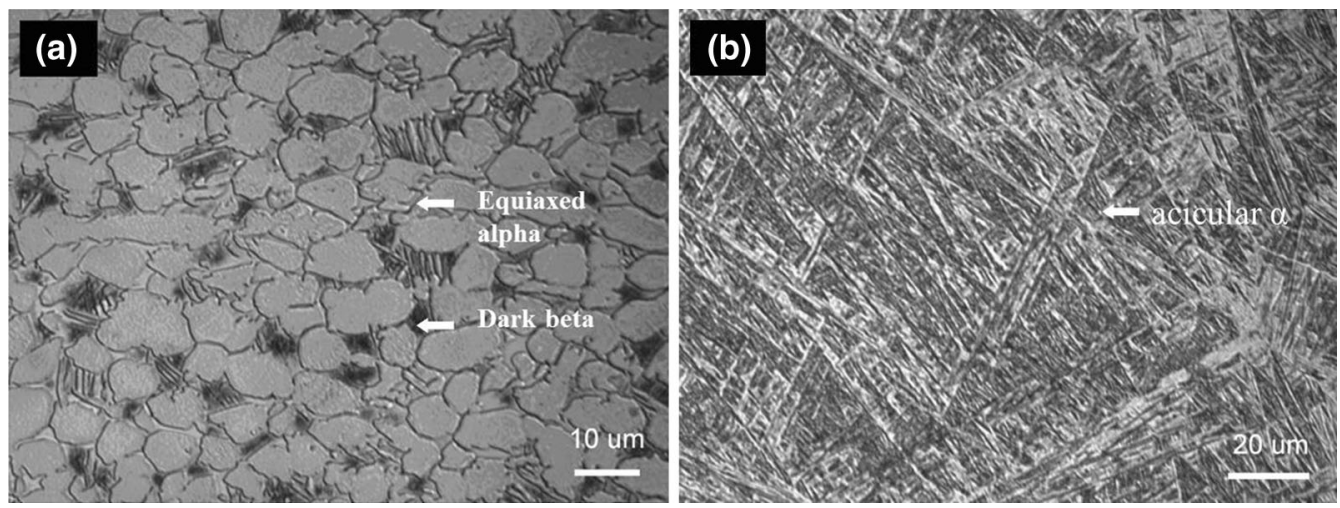

Fig. 1-Light micrographs showing $(a)$ the as-received microstructure, and $(b)$ the same material after heat treatment of $1223 \mathrm{~K}\left(950{ }^{\circ} \mathrm{C}\right) /$ $10 \mathrm{~min}+1303 \mathrm{~K}\left(1030^{\circ} \mathrm{C}\right) / 2$ min followed by water quenching.

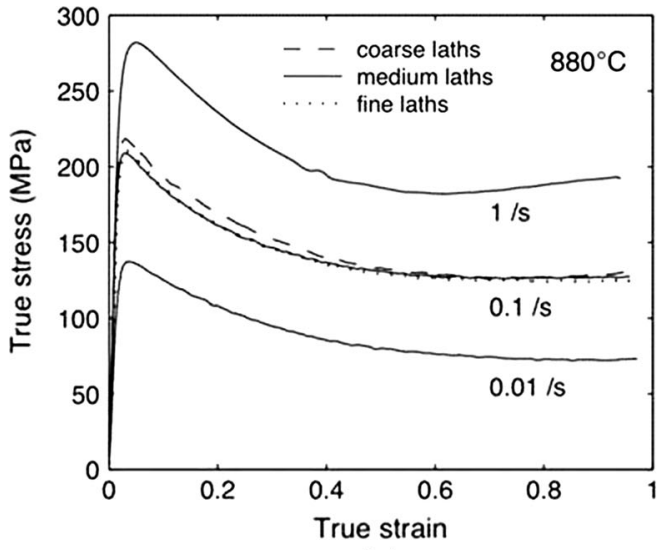

(a)

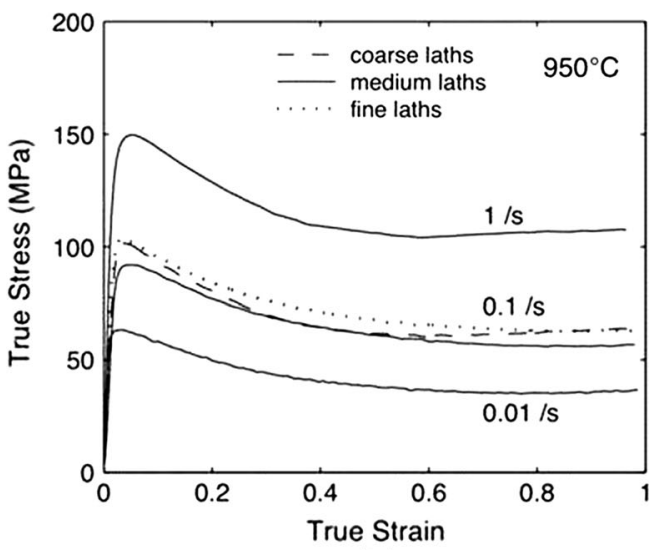

(b)

Fig. 2-Flow curves of Ti-6Al-4V with acicular initial microstructure at $(a) 1223 \mathrm{~K}\left(950{ }^{\circ} \mathrm{C}\right)$ and $(b) 1153 \mathrm{~K}\left(880{ }^{\circ} \mathrm{C}\right)$ at strain rates of $0.01,0.1$, and $1 / \mathrm{s}$. 
sectioned axially (at one-third of the deformed specimen height, indicative of the average deformation) and prepared for EBSD analysis. EBSD analysis was carried out using a Zeiss field emission gun scanning electron microscope, and orientation maps were constructed from orientation data using MTEX texture analysis software. ${ }^{[8]}$

\section{RESULTS AND DISCUSSION}

Microstructure and orientation map results showed a marked dependence on forging temperature due to the associated variation in the volume fractions of the alpha and beta phases. It is understood from previous work. ${ }^{\text {[9] }}$ The volume fraction of alpha at $1153 \mathrm{~K}\left(880{ }^{\circ} \mathrm{C}\right)$ was $\sim 0.70$ and $\sim 0.30$ at $1223 \mathrm{~K} \quad\left(950{ }^{\circ} \mathrm{C}\right)$. It is also
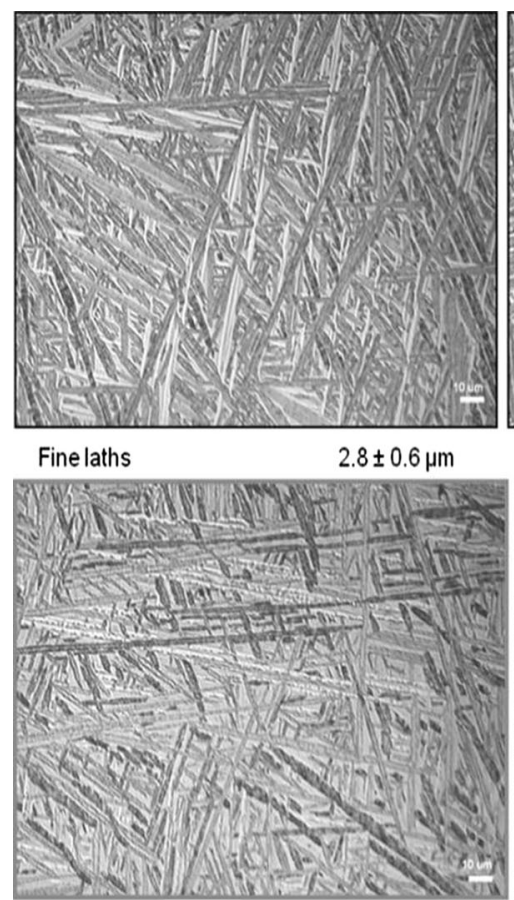

Fine laths $\quad 50 \mu \mathrm{m} \quad 2.3 \pm 0.7 \mu \mathrm{m}$
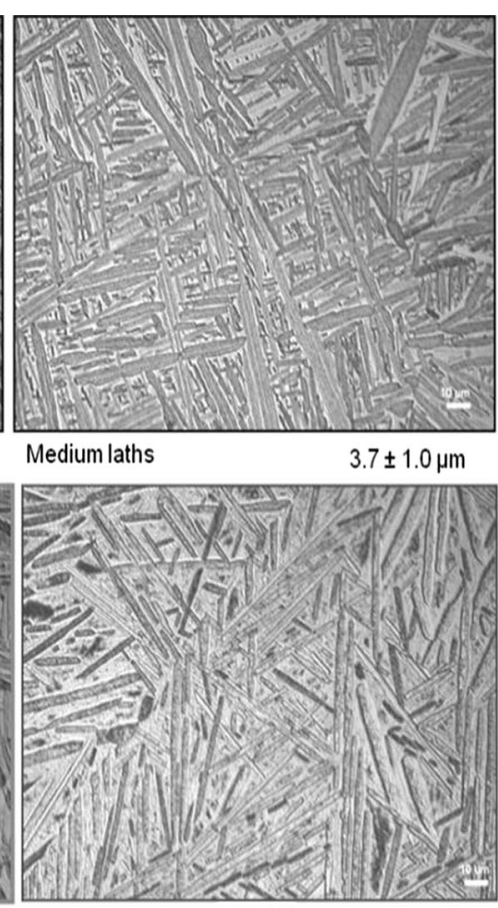

Medium laths $\quad 50 \mu \mathrm{m} \quad 2.9 \pm 0.8 \mu \mathrm{m}$
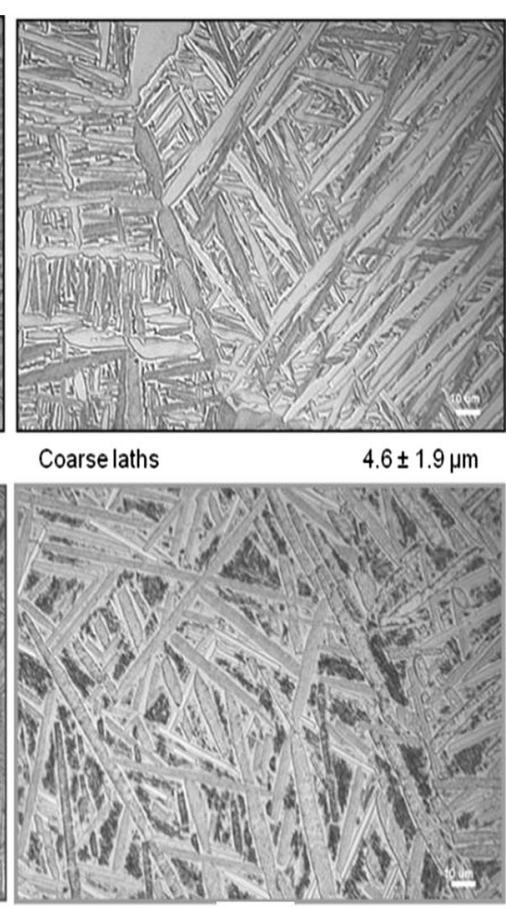

Coarse laths $\quad 50 \mu \mathrm{m}$

$4.0 \pm 1.2 \mu \mathrm{m}$

Fig. 3- Light micrographs of preheated microstructure of fine, medium, and coarser laths at $1153 \mathrm{~K}\left(880{ }^{\circ} \mathrm{C}\right)$ and $1223 \mathrm{~K}\left(950{ }^{\circ} \mathrm{C}\right)$ soaked for $30 \mathrm{~min}$ followed by water quenching.
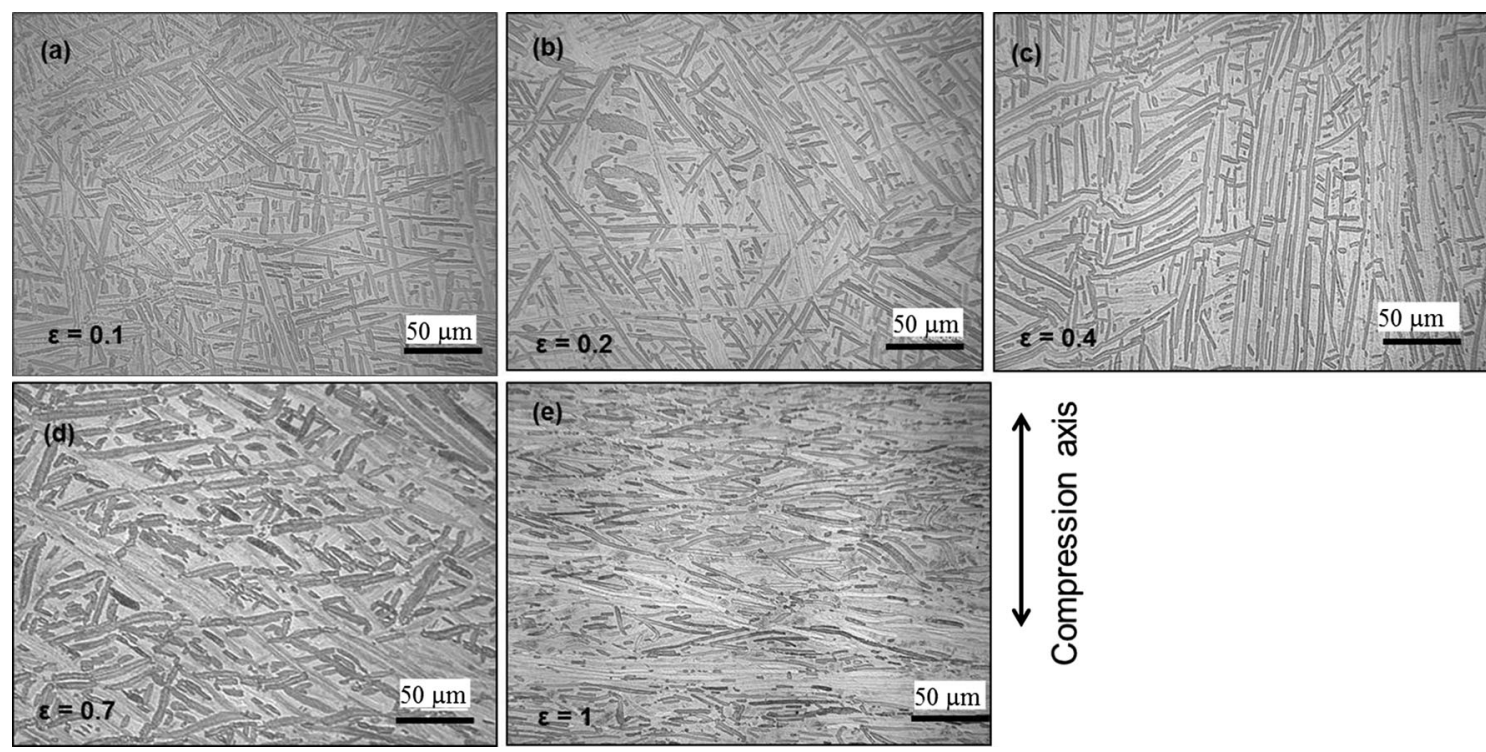

Fig. 4-Optical micrographs show the microstructure evolution of medium alpha lath of Ti-6Al-4V at $1223 \mathrm{~K}\left(950{ }^{\circ} \mathrm{C}\right)$ and at constant strain rate of $0.1 / \mathrm{s}(a) \varepsilon=0,(b) . \varepsilon=0.2,(c) \varepsilon=0.4,(d) \varepsilon=0.7$, and $(e) \varepsilon=1.0$. 

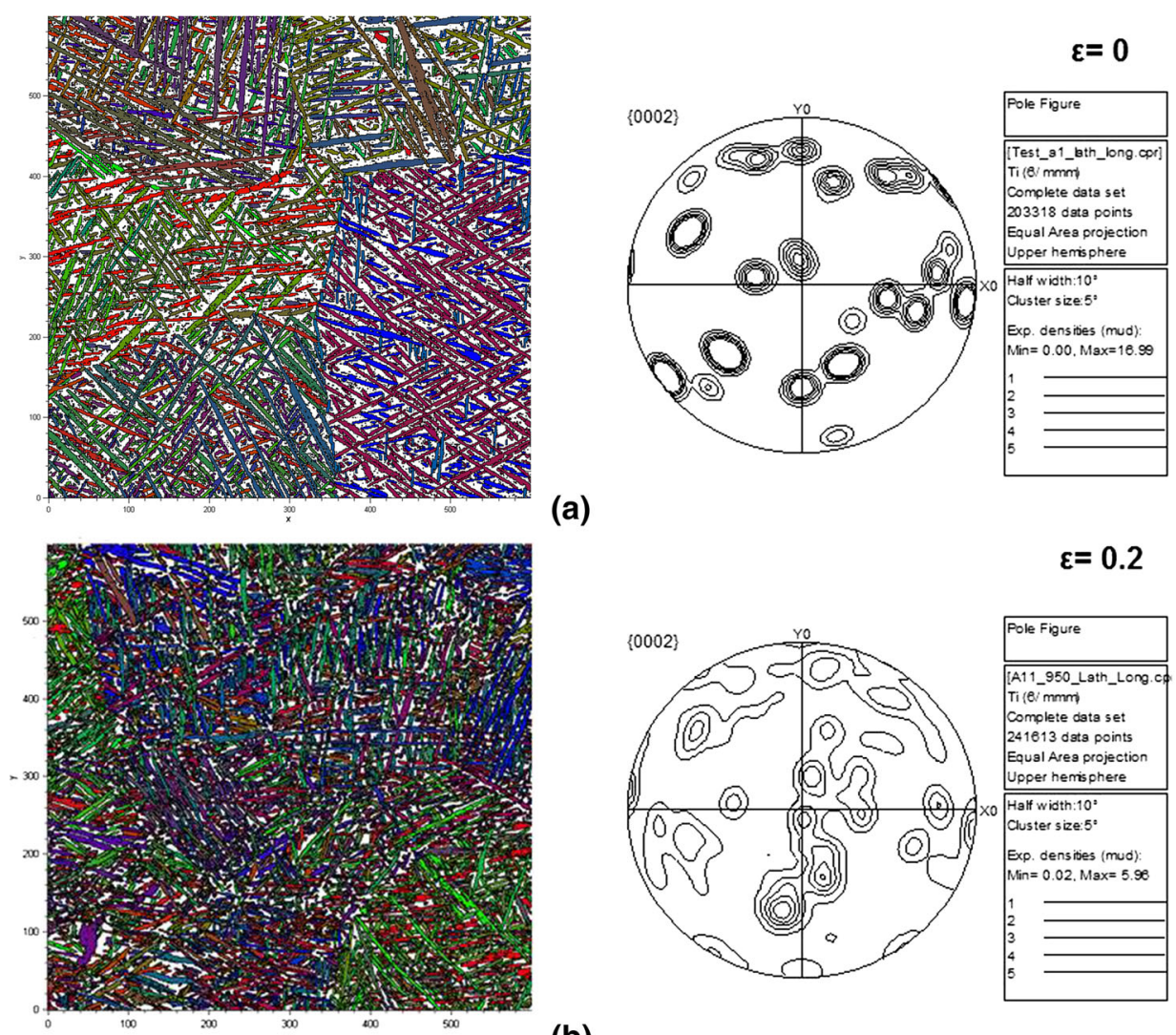

(a)

$$
\varepsilon=0.2
$$

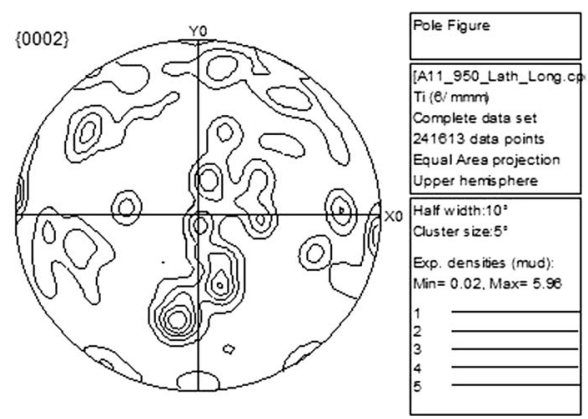

(b)
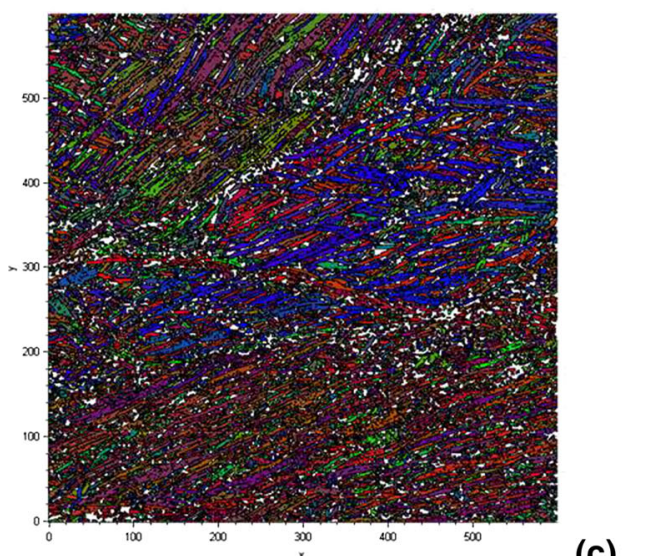

(c)
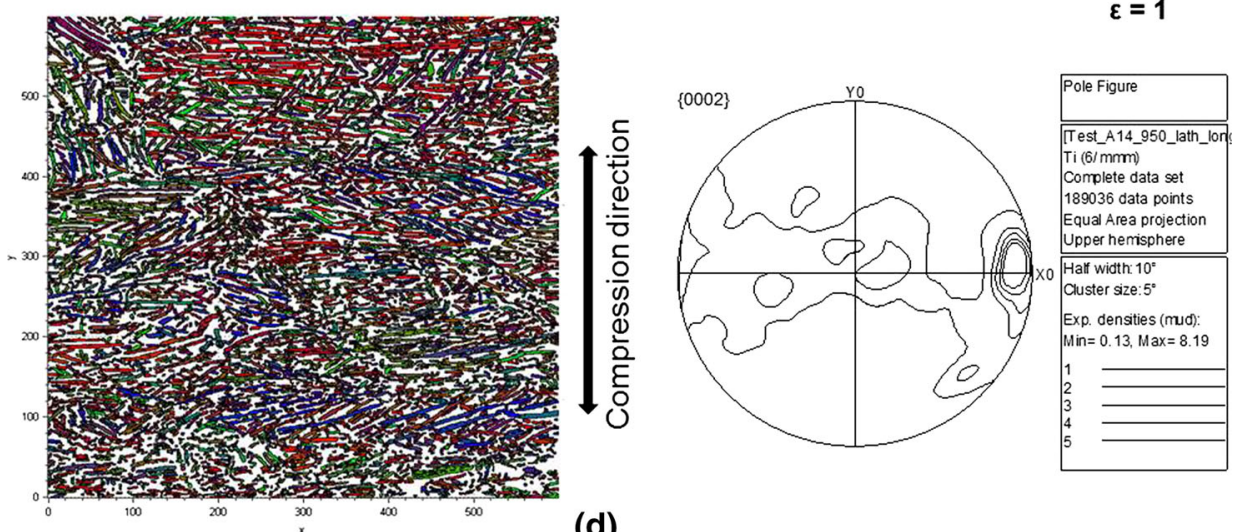

(d)

Fig. 5-The EBSD grain mapping and orientation of alpha laths on medium alpha lath of Ti-6Al-4V at $1223 \mathrm{~K}\left(950{ }^{\circ} \mathrm{C}\right)$ and $0.1 / \mathrm{s}$ with various strains $(a) \varepsilon=0,(b) \varepsilon=0.2,(c) \varepsilon=0.7$, and $(d) \varepsilon=1.0$. 

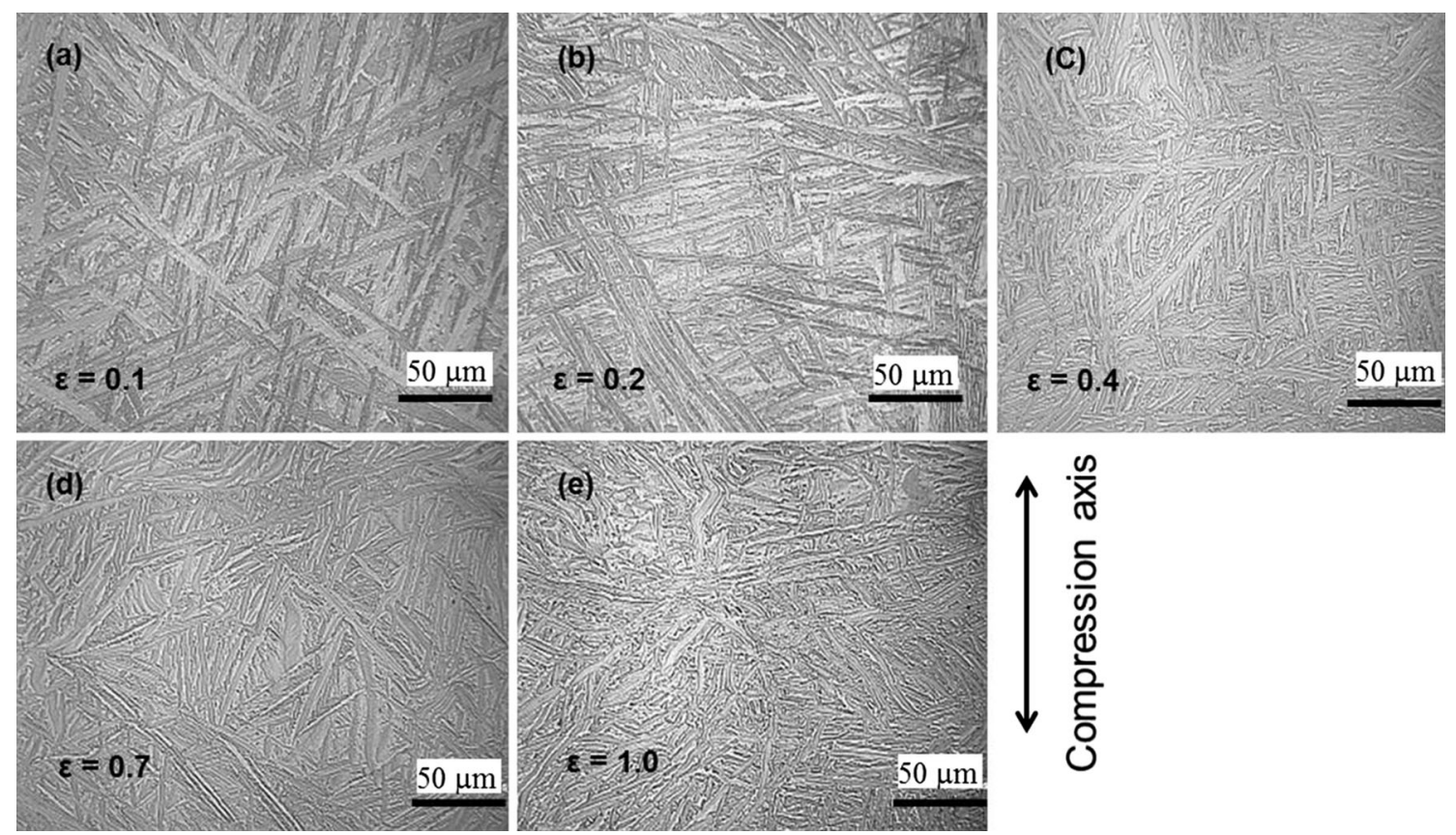

Fig. 6 - Optical micrographs of medium alpha lath of Ti-6Al-4V deformed with various strains at $1153 \mathrm{~K}\left(880{ }^{\circ} \mathrm{C}\right)$ and $0.1 / \mathrm{s}$.

understood that the difference in the volume fraction of alpha and beta affects the relative partitioning of strain between the two phases. ${ }^{[10]}$

\section{A. Flow Stress Behavior of Ti-6Al-4V}

The flow stress curves derived from hot isothermal testing of Ti-6Al-4V with the acicular initial microstructure at both sub-transus $1153 \mathrm{~K}\left(880^{\circ} \mathrm{C}\right)$ and near-transus temperatures $1223 \mathrm{~K}\left(950{ }^{\circ} \mathrm{C}\right)$ with the three different strain rates $(0.01,0.1$, and $1 / \mathrm{s})$ are presented in Figure 2. In particular, the hot deformation behavior of the 'medium' thickness alpha lath microstructure at $1153 \mathrm{~K}$ and $1223 \mathrm{~K}\left(880{ }^{\circ} \mathrm{C}\right.$ and $\left.950{ }^{\circ} \mathrm{C}\right)$ is shown for all strain rates (solid lines); the $0.1 / \mathrm{s}$ tests have been repeated at the same temperature for the 'fine' and 'coarser' microstructures marked as dotted and dashed lines, respectively, in Figure 2. These curves clearly indicate that the flow stress was strongly dependent on temperature and applied strain rate. All the flow curves showed the characteristic features of strong initial strain hardening, a broad peak at low strains, followed by moderate to extensive flow softening beyond the peak stress until a steady-state stress was reached.

This type of behavior is well documented in the literature on the hot deformation of Ti-6Al-4V with an acicular structure. ${ }^{[11,12]}$ It can be noted that the influence of the three different ('coarse', 'medium,' and 'fine') acicular microstructures showed little effect on the flow softening and only a minor effect on strain rate. The flow softening effect was slightly more pronounced at $1223 \mathrm{~K}\left(950{ }^{\circ} \mathrm{C}\right)$. The insensitivity of flow behavior to initial microstructure is surprising given that alpha lath thickness has been successfully used as an indicator for the progress of dynamic spheroidization of the alpha phase during hot forging of Ti-6Al-4V. ${ }^{[13]}$
Our systematic investigation of the hot deformation behavior of Ti-6Al-4V at $1153 \mathrm{~K}$ and $1223 \mathrm{~K}\left(880{ }^{\circ} \mathrm{C}\right.$ and $950^{\circ} \mathrm{C}$ ), using a range of initial lamellar microstructures has proved that there is little influence of alpha lath thickness on overall flow behavior for the range considered (Figure 3). Therefore, the significant flow softening observed for all deformation conditions is believed to be associated with spheroidization of the lamellar structure and also progressive realignment of alpha laths with their long axes perpendicular to the uniaxial compressive loading axis, which appear to coincide with the attainment of the steady-state flow stress.

\section{B. Isothermal Forging at $1223 \mathrm{~K}\left(950^{\circ} \mathrm{C}\right)$}

The microstructure evolution with strain of Ti-6Al-4V during isothermal forging at $0.1 \mathrm{~s}^{-1}$ at a deformation temperature of $1223 \mathrm{~K}\left(950^{\circ} \mathrm{C}\right)$ with the alloy showing the 'medium' alpha lath microstructure is shown in Figures 4(a) through (e).

It appears that the behavior of deformation and transformation of the prior alpha lamellar phase is very complex at this processing temperature. From Figures 4(a) through (e), it can be noted that some of the lamellar $\alpha$ phases have been distorted during hot working and with the increasing strain showed that the break-up of the prior $\alpha$ started at a strain $>0.2$ (Figure 4(c)). It is evident from Figures 4(a) through (e) that, at $1223 \mathrm{~K}\left(950{ }^{\circ} \mathrm{C}\right)$, there is significant distortion in the lath structure, and many laths have undergone fragmentation leading to a change in aspect ratio, indicative of the early stages of progressive globularization. It is more apparent that laths have a tendency to become aligned with their long axes perpendicular to the direction of compressive loading at a strain of 1 . 

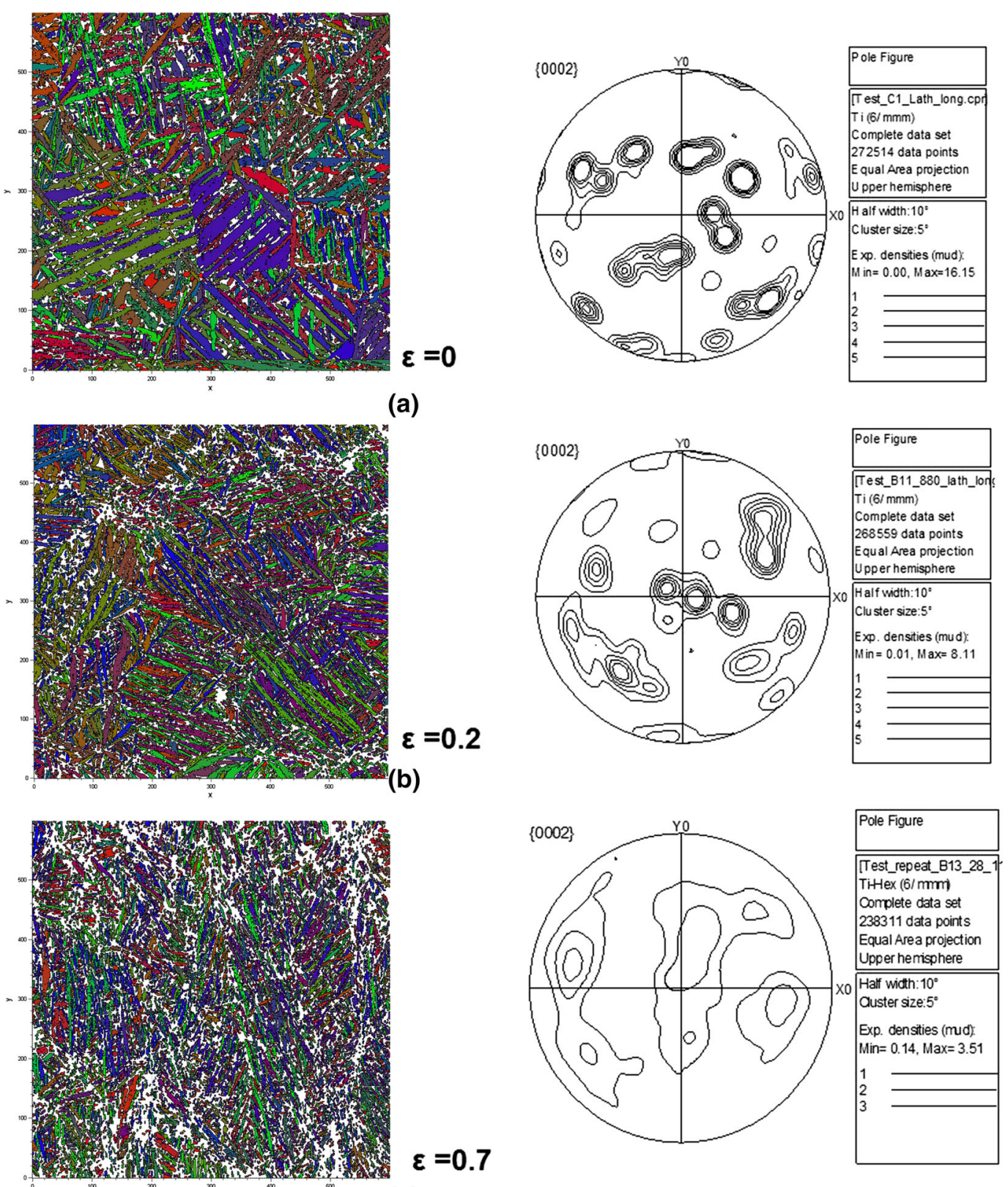

(c)
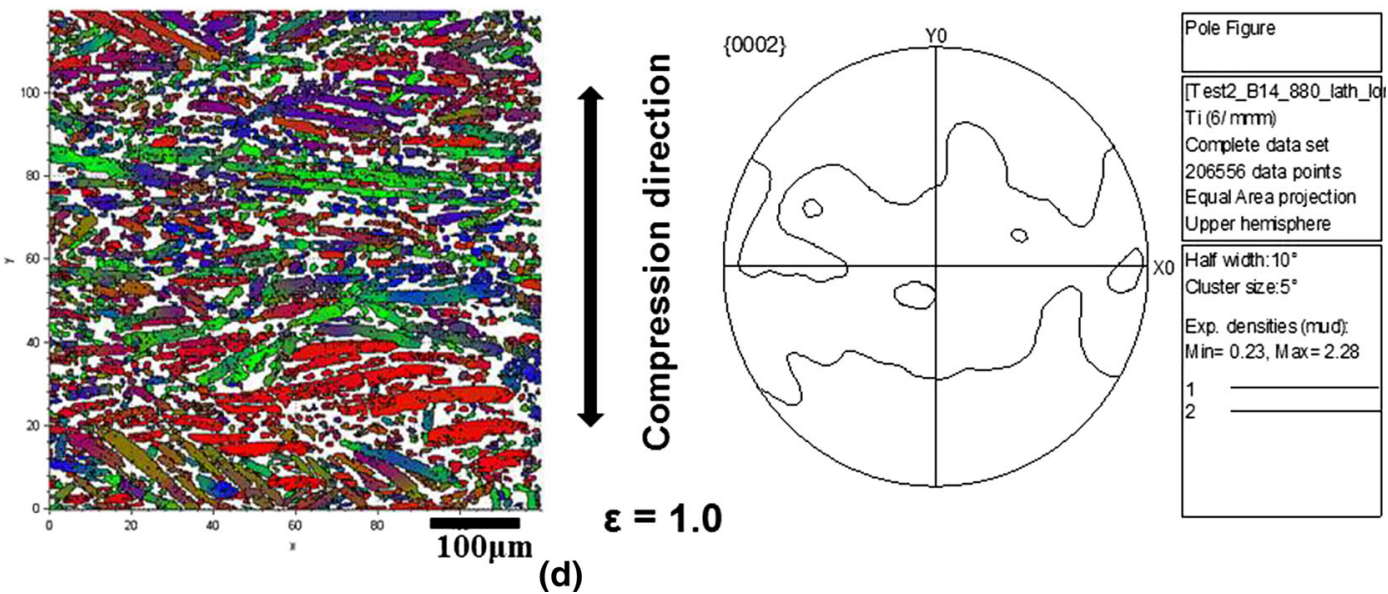

(d)

Fig. 7-The EBSD grain mapping and orientation of alpha laths on medium alpha lath of Ti-6Al-4V at $1153 \mathrm{~K}\left(880{ }^{\circ} \mathrm{C}\right)$ and $0.1 / \mathrm{s}$ with various strains $(a) \varepsilon=0,(b) \varepsilon=0.2, \varepsilon=0.7$, and $(d) \varepsilon=1.0$. 


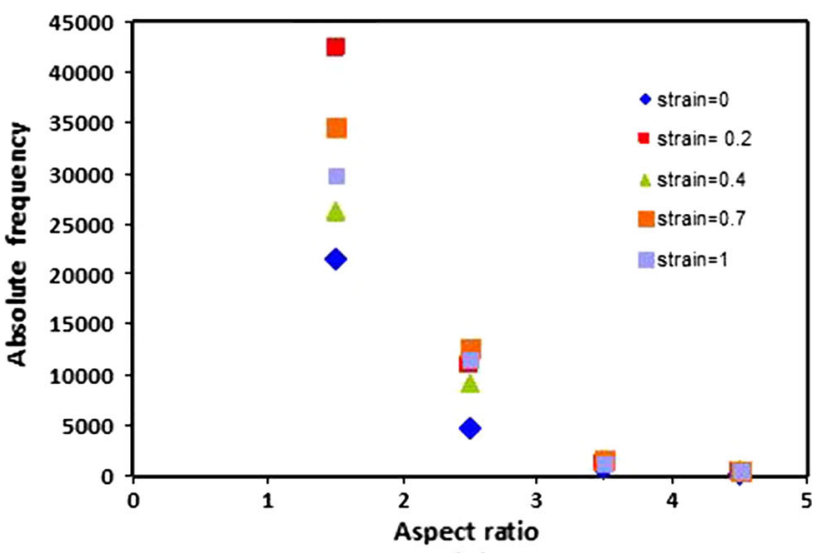

(a)

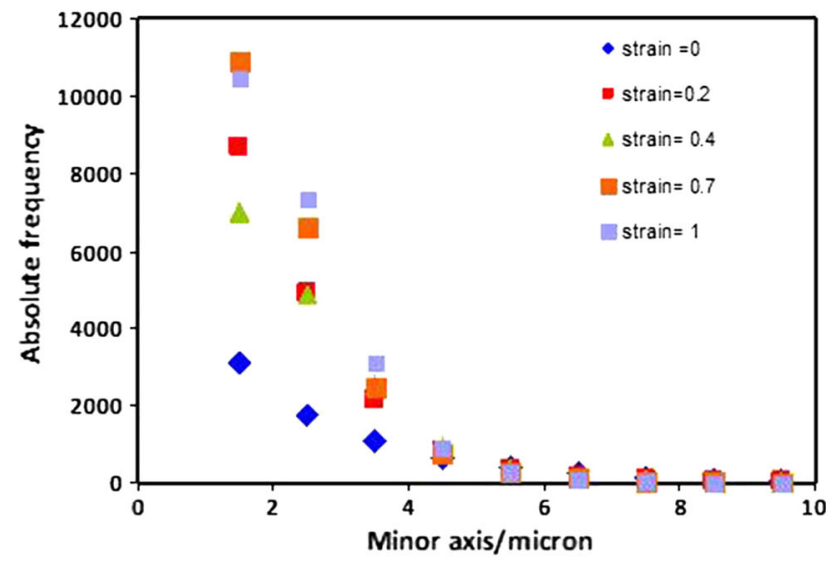

(b)

Fig. 8-Frequency distribution of $\alpha$ laths aspect ratio during isothermal forging at $1153 \mathrm{~K}\left(880^{\circ} \mathrm{C}\right)$ and strain rate of $0.1 / \mathrm{s}$. (a) Absolute frequency $v s$ Aspect ratio (b) Absolute frequency vs minor axis/micron.

In order to carry out a quantitative examination of changes in lath morphology, orientation image maps were constructed from EBSD patterns of the hcp alpha phase in the same transverse plan as the optical micrographs. These measurements were made using a step size of $1 \mu \mathrm{m}$, small enough to enable identification of primary alpha laths with thicknesses above $\sim 1 \mu \mathrm{m}$, while also being large enough to enable coverage of a significant area, $600 \mu \mathrm{m} \times 600 \mu \mathrm{m}$, which encompassed several alpha colonies in a reasonable period of time. All of the alpha maps were constructed by drawing boundaries between regions of alpha phase with orientation differences greater than $10 \mathrm{deg}$. Grains with a perimeter less than $10 \mu \mathrm{m}$ are not shown. The alpha lath morphology of initial pre-tested and deformed 'medium' thickness $\alpha$-lath microstructure of Ti-6Al-4V at $0.1 / \mathrm{s}$ with various strains $(0.0,0.2,0.7$, and 1.0$)$ are presented in Figure 5. In Figure 5(a), the alpha phase evolution of pre-tested acicular microstructure shows a random orientation of alpha laths for strains of $0.0,0.2$, and 0.7 , predominately very strong in one direction with the increasing strain $(\varepsilon=1)$ and at constant strain rate of $0.1 / \mathrm{s}$ (Figure $5(\mathrm{~d})$ ). Therefore, the effect of deformation temperature and increasing strain can rotate and break the laths toward the direction perpendicular to the

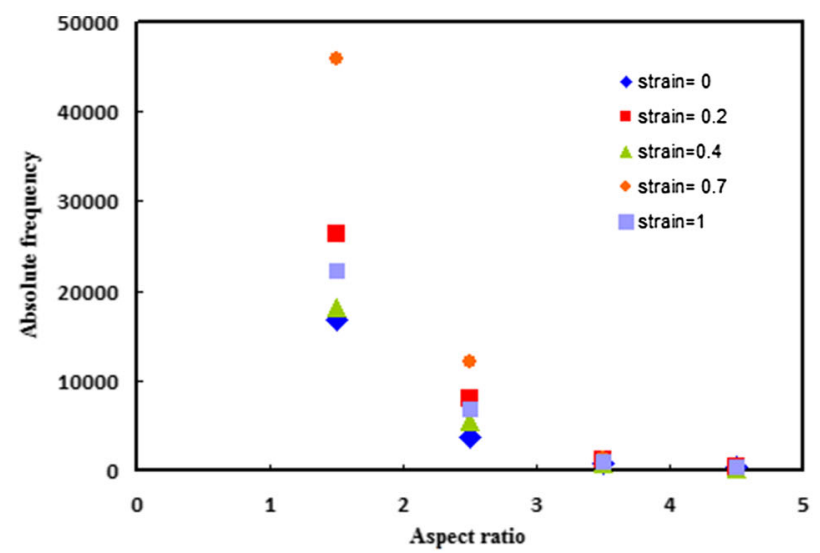

(a)

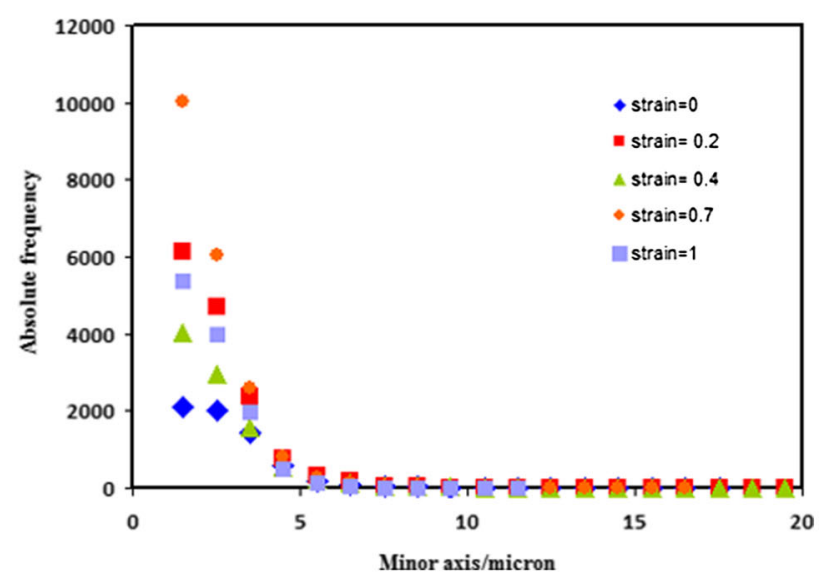

(b)

Fig. 9-Frequency distribution of $\alpha$ laths aspect ratio during isothermal forging at $1223 \mathrm{~K}\left(950^{\circ} \mathrm{C}\right)$ and $0.1 / \mathrm{s}$. (a) Absolute frequency $v s$ aspect ratio (b) Absolute frequency vs minor axis/micron.

loading axis. The orientation of alpha laths at a strain of 1.0 and strain rate of $0.1 / \mathrm{s}$ indicates a strong single pole orientation toward transverse direction and also shows an increase in pole intensity as compared to lower strain levels. This clearly indicate that laths remain fairly randomly oriented during the early stages of deformation, until well past the peak stress $(\varepsilon=0.2)$, but then became strongly aligned with their long axes perpendicular to the direction of loading $(\varepsilon=1.0)$

\section{Isothermal Forging at $1153 \mathrm{~K}\left(880^{\circ} \mathrm{C}\right)$}

The effect of strain on the microstructure evolution of Ti-6Al-4V observed during isothermal forging at $1153 \mathrm{~K}\left(880^{\circ} \mathrm{C}\right)$, at constant strain rate of $0.1 \mathrm{~s}^{-1}$ and strains of $0.1,0.2,0.4,0.7$, and 1.0 for 'medium' alpha lath were studied, and the results are shown in Figures 6(a) through (e). Stress-strain curves of the Ti-6Al-4V alloy with 'medium' thickness alpha laths compressed at $1153 \mathrm{~K}\left(880{ }^{\circ} \mathrm{C}\right)$ at a nominal strain rate of $0.1 / \mathrm{s}$ exhibited an initial hardening transient, a peak flow stress, and then flow softening (Figure 2(b)). Such behavior in single-phase metallic materials is commonly associated with discontinuous dynamic recrystallization, 
i.e., the nucleation and growth of new grains. ${ }^{[14]}$ But, for two-phase $(\alpha+\beta)$ titanium alloys with a lamellar initial structure, flow softening can be associated with the rotation of lamellae toward "softer" orientations with slip transmission across the $\alpha / \beta$ interfaces. ${ }^{[14,15]}$

At $1153 \mathrm{~K}\left(880{ }^{\circ} \mathrm{C}\right)$, the fragmentation and globularization of the $\alpha$ phase during deformation are more difficult to detect, owing to its large volume fraction. The increase in alpha phase volume has developed coarser alpha lamellar after water quenching. This illustrates that the extra 30 minutes soak at $1153 \mathrm{~K}$ $\left(880{ }^{\circ} \mathrm{C}\right.$ ) can lead to $\beta \rightarrow \alpha$ transformation which in turn increases the volume fraction of $\alpha$-phase. During compression at $1153 \mathrm{~K}\left(880{ }^{\circ} \mathrm{C}\right)$, the microstructure evolution comprised an elongation of the $\beta$ grains and rotation of the $\alpha$ lamellae toward the metal flow direction. There are bent $\alpha$ lamellae observed in $\alpha$ colonies in which the lamellae were close to being parallel to the compression axis. The microstructure observation at $1153 \mathrm{~K}\left(880{ }^{\circ} \mathrm{C}\right)$ clearly indicates that with increasing strain the initial uniform lath structure has undergone significant distortion including bending and kinking. This is noticed most in those laths which lie almost parallel to the (vertical) direction of loading. This particular mode of mechanical lath deformation is well documented. ${ }^{[15,16]}$ Those laths in the colonies which are initially aligned with the flow direction-i.e., perpendicular to the compression axis-have undergone little morphological change during deformation. At $\varepsilon=1.0$, almost all of the lamellae had become aligned with the metal flow direction (Figure 6(e)), confirming that the degree of lamellar rotation increased with strain. The work by Semiatin et al. ${ }^{[17]}$ found that microstructure evolution of Ti-6Al-4V on deformation at $1153 \mathrm{~K}$ $\left(880{ }^{\circ} \mathrm{C}\right)$ was mainly associated with the common processes of $\alpha$ platelet pinch-off/fragmentation and subsequent globularization of the remnant lamellae by termination migration.

The alpha phase evolution of the pre-tested acicular microstructure shows random orientation with other weak orientations, seen as faint dots. Figure 7(a) shows the orientation of grains at strain $=0$, where the random orientation of laths which is similar to the grain orientation map at $\varepsilon=0$. At $\varepsilon=0.2$, three strong orientations of laths were observed in Figure 7(b), one dominant and the other two less so. With the increase in strain $(\varepsilon=0.4 \& \varepsilon=0.7)$, it is seen that the previous three strong orientations were joined together to form an intermediate single orientation of laths (Figures 7(c) and (d)). In Figure 7(d), it is noted that increasing the imposed strain can rotate the $\alpha$-laths and make them align in the direction perpendicular to the hot compression direction. The significant feature in Figure 7(d) is that the intensity is only $2 \times$ random (others are nearly $10 \times$ random). This correlates with the higher amount of spheroidization. The grain measurements are easily extracted by fitting an ellipse to each grain shape, which allows a statistical examination of changes in lath orientation and aspect ratio to be undertaken. The frequency distribution of the $\alpha$-lath orientation at various strain levels during isothermal forging at $1223 \mathrm{~K}$ and $1153 \mathrm{~K}\left(950{ }^{\circ} \mathrm{C}\right.$ and $\left.880{ }^{\circ} \mathrm{C}\right)$ at $0.1 / \mathrm{s}$ have been summarized in Figures 8(a) and (b), 9(a) and (b). This also confirms that the average grain size is nearly the same with increasing strain rate at $1153 \mathrm{~K}\left(880{ }^{\circ} \mathrm{C}\right)$, with only a slight tendency to increase with the increasing strain.

\section{CONCLUSIONS}

1. Hot compression behavior of a commercial grade Ti-6Al-4V with an acicular starting microstructure has been characterized with the help of isothermal compression tests at both near-transus $(1223 \mathrm{~K}$ $\left(950{ }^{\circ} \mathrm{C}\right)$ ) and sub-transus temperatures $(1153 \mathrm{~K}$ $\left.\left(880^{\circ} \mathrm{C}\right)\right)$ with various strain levels $(0.1,0.2,0.4,0.7$, and 1.0) and strain rate range $\left(0.01-1.0 \mathrm{~s}^{-1}\right)$.

2. Significant flow softening, observed for all deformation conditions, was not solely associated with globularization of the lamellar structure. Instead, progressive realignment of the alpha laths with their long axes perpendicular to the uniaxial compressive loading axis appears to coincide with the attainment of a steady-state flow stress.

3. Microstructure evolution during deformation of Ti-6Al-4V is motivated mainly by the imposed strain and by kinking of the $\alpha$ lamellae. If the long axes of alpha laths are perpendicular to the loading direction, the $\alpha$ laths are kinked. Otherwise, the $\alpha$ laths rotate with strain, tending to became aligned perpendicular to the loading direction, and their thickness is reduced somewhat.

4. Correlation of experimental results such as flow softening and microstructure evolutions of Ti-6Al-4V has shown that the rotation of the lamellar microstructure occurs during hot working.

\section{ACKNOWLEDGMENTS}

We gratefully acknowledge the financial support of QinetiQ. The neutron diffraction experiments were performed at the UK ISIS neutron source, and we are grateful to the Science and Technology Facilities Council for awarding beam time. MEF is grateful for the support of the Lloyd's Register Foundation, a charitable foundation helping protect life and property by supporting engineering-related education, public engagement, and the application of research.

\section{OPEN ACCESS}

This article is distributed under the terms of the Creative Commons Attribution 4.0 International License (http://creativecommons.org/licenses/by/4.0/), which permits unrestricted use, distribution, and reproduction in any medium, provided you give appropriate credit to the original author(s) and the source, provide a link to the Creative Commons license, and indicate if changes were made. 


\section{REFERENCES}

1. S.L. Semiatin, J. Thomas, and P. Dadras: Metall. Mater. Trans. A, 1983, vol. 14A, pp. 2363-74.

2. I. Weiss, F. Froes, D. Eylon, and G. Welsch: Metall. Mater. Trans. A, 1986, vol. 17A, pp. 1935-47.

3. J.G. Malcor, F. Montheillet, and B. Champin: in Titanium: Science and Technology, G. Luetjering, ed., Oberursel, Germany, 1985, pp. $1495-1502$.

4. T.H. Courtney and J.C. Malzahn Kampe: Acta Metall., 1989, vol. 37 , pp. $1747-58$.

5. T.H. Courtney and R.J. Comstock, Jr.: in Modeling of Coarsening and Grain Growth, C.S. Pande and S.P. Marsh, eds., TMS, Warrendale, 1993 , p. $71-84$.

6. G. Sharma, R.V. Ramanujan, and G.P. Tiwari: Acta Mater., 2000, vol. 48, pp. 875-89.

7. Y.G. Nakagawa and G.C. Weatherly: Metall. Trans., 1972, vol. 3, pp. 3223-29.

8. R. Hielscher and H. Schaeben: J. Appl. Cryst., 2008, vol. 41, pp. 1024-37.
9. S. Semiatin et al:: Metall. Mater. Trans. A, 2003, vol. 34 (10), pp. $2377-86$.

10. S.L. Semiatin, F. Montheillet, G. Shen, and J.J. Jonas: Metall. Mater. Trans. A, 2002, vol. 33A, pp. 2719-27.

11. E.B. Shell and S.L. Semiatin: Metall. Mater. Trans., 1999, vol. 30A, pp. 3219-29.

12. T. Seshacharyulu, S.C. Medeiros, W.G. Frazier, and Y.V.R.K. Prasad: Mater. Sci. Eng. A, 2002, vol. 325, pp. 11225.

13. A.F. Wilson, V. Venkatesh, R. Pather, J.W. Brooks, and S.P. Fox: in Ti-2003: Science and Technology, G. Luetjering and J. Albrech, eds., Wiley, New Jerssey, 2004, p. 321329.

14. R.M. Miller, T.R. Bieler, and S.L. Semiatin: Scripta Mater., 1999, vol. 40 (12), pp. 1387-93.

15. S.L. Semiatin, V. Seetharaman, and I. Weiss: Mater. Sci. Eng. A., 1999, vol. 63, pp. 257-71.

16. T.R. Bieler and S.L. Semiatin: Int. J. Plast, 2002, vol. 18 (9), pp. 1165-89.

17. S. Zherebtsov, M. Murzinova, G. Salishchev, and S.L. Semiatin: Acta Mater., 2011, vol. 59 (10), pp. 4138-50. 